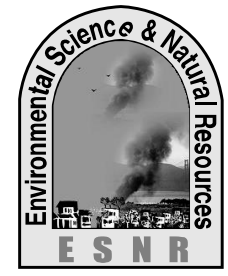

\title{
Impact of Climate Change on Wheat Production in Dinajpur Region of Bangladesh: an Econometric Analysis
}

\author{
J.A. Syeda \\ Department of Statistics \\ Hajee Mohammad Danesh Science and Technology University, Dinajpur \\ Corresponding author: jasyeda@yahoo.com
}

\begin{abstract}
Dinajpur is the highest wheat producing northern district in Bangladesh and wheat is the second most essential cereal crop after rice in this country. This is much sensitive to climatic change. The main concern of this paper was to quantify the long-term effect of climate change on wheat production in Dinajpur district using multiple regression analysis technique taking several climatic variables for 1948-2004. The approximately significant effects were found for the climatic variables of average minimum temperature (tmn), average dry bulb temperature (td) and total rainfall (ttr) on wheat production. It may be reported that one percent increase in tmn increases the yield rate by about $2.62 \%$, one percent increase in td decreases the yield rate by about $2.58 \%$ and one percent increase in tr increases the yield rate by about $0.03 \%$.
\end{abstract}

Key words: Climate change, Econometric analysis, Wheat

\section{Introduction}

The global mean temperature has risen by $7^{\circ} \mathrm{C}$ since 1860. Over the same period, $\mathrm{CO}_{2}$ concentrations have increased by 46 percent. Global agriculture will face the problems of changing climate in coming decades. Crop yield growth has slowed since 1990. On the other hand, the world population will be double by the year 2060. Despite technological advances such as improved crop varieties and irrigation systems, climate is still the key factor for agricultural productivity. Furthermore, climate may vary and change with time and space but warming may also affect agriculture sector as a whole through changing yields, changing water availability, affecting soil condition, etc. The effect of climate on agricultural productions is important for local, regional, national and global scales. Wheat yield is much sensitive to climate variation and change as the temperature variation is the notable factor for wheat cultivation. There is no universal accepted approach for the assessment the impacts of climate change on agriculture. The three approaches are: (1) Crop yield analysis, (2) Spatial analysis (3) Agriculture system analysis. Impact of climate change on crop growth, development, water use and productivity of crop can be quantified by the measurement of direct effects of modified weather parameters and $\mathrm{CO}_{2}$ on crop growth in phytotron, glass houses, etc. but these approaches are costly. You L. et al. (2005) assessed the impact of climate change on wheat production in China through crop yield analysis where regression technique is used for the historical panel data. Wheat is the second most important cereal crop after rice in Bangladesh and Dinajpur is the highest wheat producing area in this country. So, the multiple regression model using historical climatic and yield data for wheat crops in Dinajpur is used to predict the changes in yields expected due to changes in climate.

A brief discussion on the necessity of the assessment for the impact of climatic change on wheat production in Dinajpur is explained in introductory section. In the section 2, the sources of data are mentioned and the methodologies applied are briefly discussed. The findings of this study are presented in the section 3 . The conclusions of this study are presented in the section 4 .

\section{Methodology}

\section{Sources of data}

The secondary data on the production and acreage of wheat were collected from the book ñA Data Base on Agriculture and Food grains in Bangladesh (1947-48 to 1989-90)ò (Hamid M. A. (1991) and ñStatistical Year Book of Bangladeshò published by the Bangladesh Bureau of Statistics (BBS, 1992). The annual data on wheat production in metric ton and in acres were collected for 1947-48 to 2003-2004. The wheat production rate in percentage (wpr) was used in the analysis and it is calculated by a simple formula: Rate $=$ (Annual wheat production / Annual cultivated area $)$ $\times 100$. Data from 1949 to 1990 were taken from the Hamid M. A. (1991) and data from 1991 to 2001 are taken from Statistical Year Book of Bangladesh. The production 13,913 metric ton in 1982 sources from Hamid M. A. (1991) was detected as outlier and that was replaced from the data $1,28,845$ metric ton recorded in the Statistical Year Book of Bangladesh (BBS,1992) which was more than 9 times bigger than 
the earlier value. Again, the highly significant structural change was detected Gujarati, D.N. (1995) in the data from 1976 and a dummy variable (dm) was used for structural change as: $\mathrm{dm}=0$ for wheat production rate before 1976 and $\mathrm{dm}=1$ for wheat production rate from 1976.

The secondary data on climatic factors of Dinajpur district during 1948-2004 for the wheat growing period (Novemberï March) are collected from the Bangladesh Meteorological Department, Dhaka, Bangladesh. But all the climatic data of Dinajpur were not available for 1973-1980 and these missing data were estimated by applying univariate Box-Jenkinôs ARIMA (autoregressive integrated moving average) modeling techniques Pankraiz (1991). The residualôs stationarity and normality were checked. The outliers were checked in these data and the detected outliers were replaced by the estimated value using the same techniques. In this research, the used climatic variables were the average minimum temperature in celcius (tmn), the average maximum temperature in celcius (tmx), the average dry bulb temperature in celcius (td), the average wet bulb temperature in celcius (tw), the frequency of average dry bulb temperature which is greater than $20^{\circ} \mathrm{C}$ (ftd), the total rainfall in millimeter (ttr), the average maximum rainfall in millimeter (mxr), the average frequency of insignificant rainfall which is less than $5 \mathrm{~mm}$ (rf), the average relative humidity in percentage (hu), the average sea level pressure in millibar (slp), the average cloud in octas (ac), the average maximum wind speed in knots (wmx), the average wind speed in knots (wv) and the average difference of morning and the afternoon relative humidity in percentage $\{\mathrm{hu}(0-12)\}$.

\section{Method}

A multiple regression model was fitted to examine for the rate of wheat production data on climatic variables during November-March over the years 1948-2004. The three regression models were estimated using three predictor sets of historical climatic data. One dummy variable was included with each predictor set as the significant structural change viewed in the response variable from 1976 what was tested according to Gujarati (1995). The predictor set 1 included 15 variables namely $\mathrm{dm}, \mathrm{tmn}, \mathrm{tw}, \mathrm{ftd}, \mathrm{ttr}, \mathrm{td}, \mathrm{hu}, \mathrm{mxr}, \mathrm{tmx}$, slp, ac, wmx, wv, hu(0-12) and rf. The predictor set 2 included 11 variables namely $\mathrm{dm}, \mathrm{tmn}, \mathrm{tw}, \mathrm{ttr}, \mathrm{td}$, hu, tmx, slp, ac, wmx and wv. The predictor set 3 contained 10 variables namely $\mathrm{dm}, \mathrm{tmn}, \mathrm{tw}, \mathrm{ftd}, \mathrm{ttr}, \mathrm{td}, \mathrm{hu}, \mathrm{tmx}$, slp and ac.

Multicollinearity was checked in the regression models for selecting the climatic variables through investigating the range of variance inflation factors (VIF). The variables were selected by using the backward elimination procedure started with full equation and dropped one variable at a time against the smallest insignificant $t$ values. This process was stopped for the minimum absolute $\mathrm{t}$ - test became greater than 1 . Draper N.R and Smith H. (1981). Normality and stationarity for residuals were also checked for selecting the variables. But the residuals followed normality and first order auto-correlated structure. So it was tried to refit and reexamine the new regression coefficients taking the autocorrelation into account. The new regression models were estimated according to Cochrane and Orcutt (1949) iterative procedure, which satisfied the assumption of uncorrelated errors with the same procedure. To obtain robust models, outliers and hi-leverage points were identified applying some modern diagnostics tools namely deleted Studentized residuals and other residual based techniques. Chatterjee, S. and Hadi, A. S. (1988). Finally the three appropriate models were obtained and among the three obtained models, one model was selected having the highest $\mathrm{F}$ and $\mathrm{R}^{2}$ values.

\section{Results}

In order to quantify the impact of climatic change on wheat production in Dinajpur district of Bangladesh, three multiple regression models are made taking several climatic variables during wheat growing period (Nov-Mar) including a dummy variable (dm). Dummy variable is taken for the structural change of wheat production data in 1976. The estimated regression coefficients for the selected (original) variables are presented in Table 1 for the three data sets 1,2 and 3 . Furthermore, Table 2 presents the regression coefficients of the models for the transformed variables. 
Table 1. Regression coefficients for the selected variables of the three data sets 1,2 and 3

\begin{tabular}{|c|c|c|c|c|c|c|c|c|c|c|c|c|c|c|}
\hline \multicolumn{4}{|c|}{ Set 1 } & \multicolumn{4}{|c|}{ Set 2 } & \multicolumn{5}{c|}{ Set 3 } \\
\hline pred & coef & sd & t & p & pred & coef & StDev & t & p & pred & coef & sd & t & p \\
\hline Const & 34.72 & 41.35 & 0.84 & 0.405 & Const & 55.69 & 40.9 & 1.36 & 0.179 & Const & 34.62 & 41.55 & 0.83 & 0.409 \\
\hline $\mathrm{dm}$ & 50.231 & 3.083 & 16.29 & 0 & $\mathrm{dm}$ & 50.267 & 3.128 & 16.07 & 0 & $\mathrm{dm}$ & 50.469 & 3.113 & 16.21 & 0 \\
\hline $\mathrm{tmn}$ & 5.965 & 1.87 & 3.19 & 0.002 & $\mathrm{tmn}$ & 5.551 & 1.854 & 2.99 & 0.004 & $\mathrm{tmn}$ & 5.881 & 1.882 & 3.12 & 0.003 \\
\hline $\mathrm{ftd}$ & -0.6013 & 0.4596 & -1.31 & 0.197 & $\mathrm{ttr}$ & 0.04692 & 0.02918 & 1.61 & 0.114 & $\mathrm{ftd}$ & -0.6301 & 0.4605 & -1.37 & 0.177 \\
\hline $\mathrm{tmx}$ & -2.621 & 1.363 & -1.92 & 0.06 & $\mathrm{td}$ & -1.55 & 1.453 & -1.07 & 0.291 & $\mathrm{ttr}$ & 0.0415 & 0.02875 & 1.44 & 0.155 \\
\hline $\mathrm{ac}$ & -8.49 & 4.674 & -1.82 & 0.075 & $\mathrm{tmx}$ & -2.332 & 1.462 & -1.6 & 0.117 & $\mathrm{tmx}$ & -2.553 & 1.375 & -1.86 & 0.069 \\
\hline $\mathrm{mxr}$ & 0.3566 & 0.2257 & 1.58 & 0.12 & $\mathrm{ac}$ & -9.342 & 4.649 & -2.01 & 0.05 & $\mathrm{ac}$ & -8.543 & 4.708 & -1.81 & 0.076 \\
\hline
\end{tabular}

Const-Constant, pred-predictor, coef-coefficient, sd-standard deviation, $t$-t value, $p$ - $p$ value

Table 2. Regression coefficients for the transformed variables of three data sets 1,2 and 3

\begin{tabular}{|c|c|c|c|c|c|c|c|c|c|c|c|c|c|c|}
\hline \multicolumn{9}{|c|}{ Set 1 } & \multicolumn{9}{|c|}{ Set 2 } & \multicolumn{4}{c|}{ Set 3 } \\
\hline pred & coef & sd & t & p & pred & coef & sd & t & p & pred & coef & sd & t & p \\
\hline const & 25.75 & 16.87 & 1.53 & 0.133 & const & 37.93 & 17.24 & 2.2 & 0.033 & const & 25.96 & 17.67 & 1.47 & 0.148 \\
\hline $\mathrm{dm}^{*}$ & 46.876 & 3.619 & 12.95 & 0 & $\mathrm{dm}^{*}$ & 47.163 & 3.725 & 12.66 & 0 & $\mathrm{dm}^{*}$ & 47.111 & 3.637 & 12.95 & 0 \\
\hline $\mathrm{tmn}^{*}$ & 2.805 & 1.904 & 1.47 & 0.147 & $\mathrm{tmn}^{*}$ & 2.675 & 2.04 & 1.31 & 0.196 & $\mathrm{tmn}^{*}$ & 2.639 & 1.915 & 1.38 & 0.174 \\
\hline $\mathrm{ftd}^{*}$ & -0.4907 & 0.4457 & -1.1 & 0.276 & $\mathrm{tr}^{*}$ & 0.04336 & 0.02131 & 2.03 & 0.047 & $\mathrm{td} *$ & -0.5244 & 0.4522 & -1.16 & 0.252 \\
\hline $\mathrm{tmx}^{*}$ & -1.875 & 1.277 & -1.47 & 0.148 & $\mathrm{td}^{*}$ & -1.81 & 1.859 & -0.97 & 0.335 & $\mathrm{ttr}^{*}$ & 0.04087 & 0.02116 & 1.93 & 0.059 \\
\hline $\mathrm{ac}^{*}$ & -3.291 & 4.084 & -0.81 & 0.424 & $\mathrm{tm}^{*}$ & -1.57 & 1.344 & -1.17 & 0.248 & $\mathrm{tmx}^{*}$ & -1.738 & 1.294 & -1.34 & 0.185 \\
\hline $\mathrm{mxr}^{*}$ & 0.3786 & 0.1681 & 2.25 & 0.029 & $\mathrm{ac}^{*}$ & -3.856 & 4.134 & -0.93 & 0.356 & $\mathrm{ac}^{*}$ & -2.998 & 4.153 & -0.72 & 0.474 \\
\hline
\end{tabular}

* is used for transformed variables

Table 3 presents the identified outliers and hi-leverage points for the regression models. Two (2) outliers (the $50^{\text {th }}$ and $56^{\text {th }}$ observations) and two (2) hi-leverage points $\left(28^{\text {th }}\right.$ and $29^{\text {th }}$ observations) were detected for all the models of the transformed variables and those unusual observations were omitted to obtain the appropriate regression models by deleting the $56^{\text {th }}$, $50^{\text {th }}, 29^{\text {th }}$ and then $28^{\text {th }}$ observations one after another. The TS plots of the deleted Studentized residuals for the regressions of the transformed variables of the

Table 3. Identification of outlier and hi-leverage points in the transformed regression models

\begin{tabular}{|c|c|c|c|c|c|c|c|c|c|c|c|c|}
\hline & \multicolumn{3}{|c|}{$\mathrm{n}=56, p=3,(3 p / n)=0.375$} & \multicolumn{3}{|c|}{$n=55 p=3,(3 p / n)=0.382$} & \multicolumn{3}{|c|}{$\mathrm{n}=54 \mathrm{p}=3,(3 \mathrm{p} / \mathrm{n})=0.389$} & \multicolumn{3}{|c|}{$\begin{array}{c}n=53 \\
p=3,(3 p / n)=0.396\end{array}$} \\
\hline & Set 1 & Set 2 & Set 3 & Set 1 & Set 2 & Set 3 & Set 1 & Set 2 & Set 3 & Set 1 & Set 2 & Set 3 \\
\hline Obs. no & 56 & 56 & 56 & 50 & 50 & 50 & 29 & 29 & 29 & 28 & 28 & 28 \\
\hline SRES1 & -2.687 & -2.722 & -2.630 & 2.694 & 2.576 & 2.617 & -1.222 & -1.655 & -1.363 & -1.446 & -1.512 & -1.374 \\
\hline TRES1 & -2.880 & -2.924 & -2.809 & 2.893 & 2.746 & 2.797 & -1.229 & -1.687 & -1.376 & -1.464 & -1.534 & -1.388 \\
\hline HI1 & 0.074 & 0.085 & 0.084 & 0.065 & 0.072 & 0.068 & 0.489 & 0.425 & 0.469 & 0.457 & 0.449 & 0.453 \\
\hline
\end{tabular}

n-o. of observation, $p=$ parameter, Obs. no-Observation number, HI-Hi-leverage points, SRES-Standardized residuals, TRES-T resid

data sets 1, 2 and 3 indicated unusual point along the $\mathrm{X}$-axis and the figures showed only one unusual point at a time in each case. NP plots for residuals followed normality and ACF displays for residuals showed non auto correlated structure (approximately) for the fitted models after deleting the 4 unusual points. Some residual figures for the data set 2 are presented [Figure 1 to Figure 12]. Table 4 presents the ANOVA (analysis of variance) results for the obtained regression models where the detected outliers and hi-leverage points had been deleted one by one. 
Table 4. ANOVA results for the regression models of data sets 1, 2 and 3 deleting UO

\begin{tabular}{|c|c|c|c|c|c|c|c|c|c|c|c|c|c|c|}
\hline \multirow{5}{*}{1} & & DF & TSS & RSS & RMS & ESS & EMS & DF & $F$ & $\mathbf{P}$ & $\mathbf{S}$ & R-Sq & R-Sq(adj) & DW \\
\hline & $56 \mathrm{O}$ del & 54 & 11028.9 & 9441.9 & 1573.6 & 1587 & 33.1 & 48 & 47.6 & 0 & 5.75 & $85.60 \%$ & $83.80 \%$ & 1.38 \\
\hline & $50 \mathrm{O}$ del & 53 & 10304.8 & 8957.7 & 1493 & 1347 & 28.7 & 47 & 52.09 & 0 & 5.354 & $86.90 \%$ & $85.30 \%$ & 1.4 \\
\hline & $29 \mathrm{HL}$ del & 52 & 10248 & 8943.8 & 1490.6 & 1304.2 & 28.4 & 46 & 52.58 & 0 & 5.325 & $87.30 \%$ & $85.60 \%$ & 1.41 \\
\hline & $28 \mathrm{HL} \mathrm{del}$ & 51 & 9578.8 & 8333.9 & 1389 & 1244.9 & 27.7 & 45 & 50.21 & 0 & 5.26 & $87.00 \%$ & $85.30 \%$ & 1.32 \\
\hline \multirow{4}{*}{2} & $56 \mathrm{O}$ del & 54 & 11316.2 & 9676.6 & 1612.8 & 1639.6 & 34.2 & 48 & 47.21 & 0 & 5.845 & $85.50 \%$ & $83.70 \%$ & 1.4 \\
\hline & $50 \mathrm{O}$ del & 53 & 10580.4 & 9167.5 & 1527.9 & 1412.9 & 30.1 & 47 & 50.83 & 0 & 5.483 & $86.60 \%$ & $84.90 \%$ & 1.42 \\
\hline & $29 \mathrm{HL} \mathrm{del}$ & 52 & 10521.7 & 9191.1 & 1531.8 & 1330.6 & 28.9 & 46 & 52.96 & 0 & 5.378 & $87.40 \%$ & $85.70 \%$ & 1.4 \\
\hline & $28 \mathrm{HL} \mathrm{del}$ & 51 & 9860.8 & 8596.3 & 1432.7 & 1264.5 & 28.1 & 45 & 50.99 & 0 & 5.301 & $87.20 \%$ & $85.50 \%$ & 1.29 \\
\hline \multirow{4}{*}{3} & $56 \mathrm{O}$ del & 54 & 11498.9 & 9847.9 & 1641.3 & 1650.9 & 34.4 & 48 & 47.72 & 0 & 5.865 & $85.60 \%$ & $83.80 \%$ & 1.42 \\
\hline & $50 \mathrm{O}$ del & 53 & 10755.7 & 9340.3 & 1556.7 & 1415.4 & 30.1 & 47 & 51.69 & 0 & 5.488 & $86.80 \%$ & $85.20 \%$ & 1.45 \\
\hline & $29 \mathrm{HL}$ del & 52 & 10695.6 & 9336.2 & 1556 & 1359.4 & 29.6 & 46 & 52.65 & 0 & 5.436 & $87.30 \%$ & $85.60 \%$ & 1.44 \\
\hline & $28 \mathrm{HL} \mathrm{del}$ & 51 & 10039.9 & 8736.2 & 1456 & 1303.7 & 29 & 45 & 50.26 & 0 & 5.382 & $87.00 \%$ & $85.30 \%$ & 1.37 \\
\hline
\end{tabular}

*UO-Unusual Observations, O del-Outlier deleted, HL del-High-Leaverage deleted, TSS-total sum square, RSS-Regression Sum Square, RMSRegression Mean Square, ESS-Error Sum Square, EMS-Error Mean Square, DW-Durbin Watson Statistic,

DF-Degrees of Freedom

Table 4 presents the finally fitted regression coefficients deleting the unusual observations. But from the regression results for all sets of data, no significant regression coefficient of climatic variables was observed at $5 \%$ level of significance. On the other hand, the significant $t$ values were found only for the coefficient of dummy $\left(\mathrm{dm}^{*}\right)$ variable. The model for the data set 2 was selected among the three models based on the highest $\mathrm{F}$ and $\mathrm{R}^{2}$ and the finally obtained coefficients of finally selected variables $\mathrm{dm}^{*}, \mathrm{tmn} *$, $\mathrm{td}^{*}, \mathrm{ttr}^{*} \mathrm{tmx}^{*} \mathrm{ac}^{*}$ are 50.58, 2.62, -2.58, 0.0312, -1.22 and -3.58 , respectively, and the corresponding $t$ values were $12.39,1.5,1.55,1.63,0.87$ and 0.99 in absolute term. The $t$ values are less than one for the coefficient of tmx* and ac*. According to the results of the model, highly significant effect was found for $\mathrm{dm}^{*}$ and approximately significant effect is obtained for the climatic variables of $\mathrm{tmn}^{*}, \mathrm{td}^{*}$ and $\mathrm{ttr}^{*}$. So, one percent increase in the dummy variable $\left(\mathrm{dm}^{*}\right)$ increases the yield rate by about $50 \%$, one percent increase in average minimum temperature (tmn) increases the yield rate by about $2.62 \%$, one percent increase in average dry bulb temperature (td) decreases the yield rate by about $2.58 \%$ and one percent increase in total rainfall (ttr) increases the yield rate by about $0.03 \%$.

Table 5. Regression coefficients for the three fitted models deleting unusual observations

\begin{tabular}{|c|c|c|c|c|c|c|c|c|c|c|c|c|c|c|}
\hline \multicolumn{5}{|c|}{ Set 1} & \multicolumn{5}{|c|}{ Set 2} & \multicolumn{5}{|c|}{ Set 3} \\
\hline pred & coef & sd & $\mathbf{t}$ & p & pred & coef & sd & $\mathbf{t}$ & $\mathbf{p}$ & pred & coef & sd & $\mathbf{t}$ & p \\
\hline const & 23.4 & 18.85 & 1.24 & 0.221 & const & 40.88 & 16.71 & 2.45 & 0.018 & const & 25.5 & 19.69 & 1.3 & 0.202 \\
\hline $\mathrm{dm}^{*}$ & 50.035 & 4.084 & 12.25 & 0 & $\mathrm{dm}^{*}$ & 50.582 & 4.081 & 12.39 & 0 & $\mathrm{dm}^{*}$ & 49.912 & 4.116 & 12.13 & 0 \\
\hline $\mathrm{tmn}^{*}$ & 2.183 & 1.647 & 1.33 & 0.192 & $\mathrm{tmn}^{*}$ & 2.62 & 1.745 & 1.5 & 0.14 & tmn* & 2.028 & 1.665 & 1.22 & 0.229 \\
\hline $\mathrm{ftd} *$ & -0.4759 & 0.4231 & -1.12 & 0.267 & $\operatorname{ttr}^{*}$ & 0.03127 & 0.01912 & 1.63 & 0.109 & $\mathrm{ftd}^{*}$ & -0.482 & 0.4313 & -1.12 & 0.27 \\
\hline $\operatorname{tmx} *$ & -1.427 & 1.397 & -1.02 & 0.313 & $\mathrm{td}^{*}$ & -2.583 & 1.667 & -1.55 & 0.128 & $\mathrm{ttr}^{*}$ & 0.03021 & 0.01942 & 1.56 & 0.127 \\
\hline $\mathrm{ac}^{*}$ & -3.316 & 3.568 & -0.93 & 0.358 & $\operatorname{tmx} *$ & -1.22 & 1.404 & -0.87 & 0.389 & $\operatorname{tmx} *$ & -1.443 & 1.428 & -1.01 & 0.317 \\
\hline mxr* & 0.3056 & 0.1539 & 1.99 & 0.053 & $\mathrm{ac}^{*}$ & -3.581 & 3.605 & -0.99 & 0.326 & $\mathrm{ac}^{*}$ & -2.924 & 3.649 & -0.8 & 0.427 \\
\hline
\end{tabular}




\section{Residual plots for data Set 2}

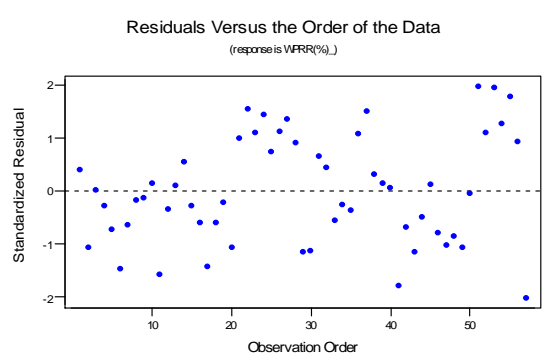

Fig. 1. SR vs order of the data for original data

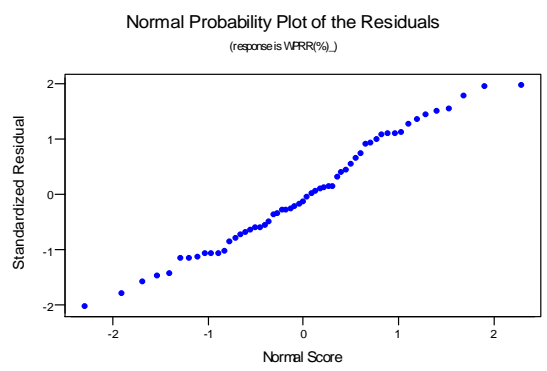

Fig. 3. Np plot of SR for original data

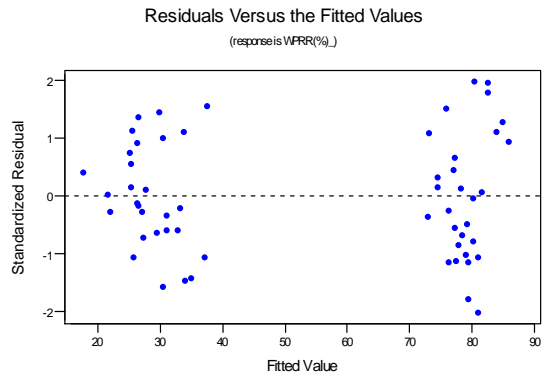

Fig. 2. SR vs fitted value for original data

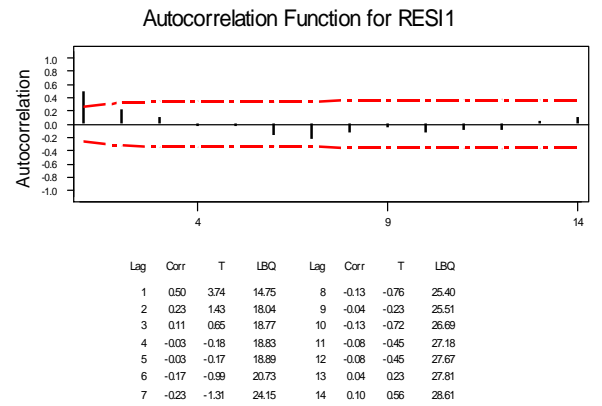

Fig. 4. ACF plot of SR for original data

Note: SR-Standardized residuals, ACF-Auto correlation function, DR-Deleted residuals, Np-Normal probability

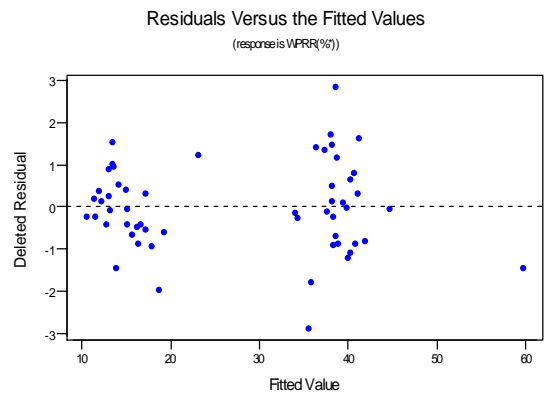

Fig. 5. DR vs fitted value for transformed data

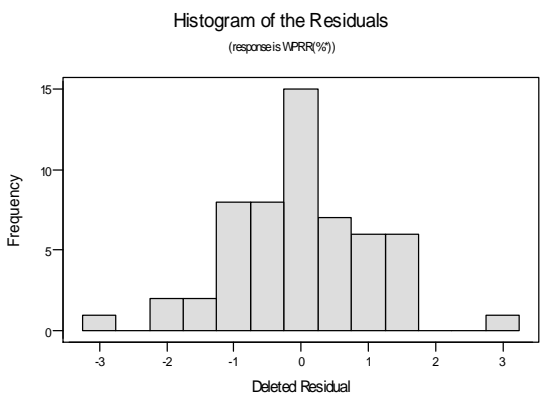

Fig. 7. Histogram of DR for transformed data

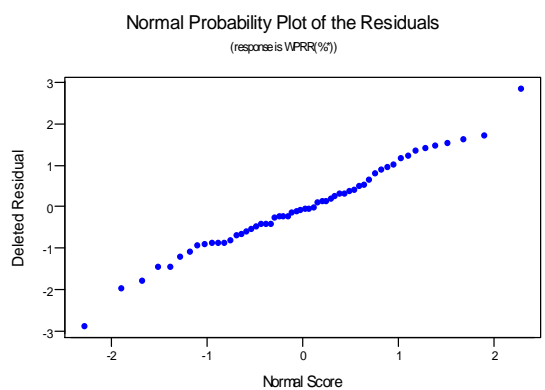

Fig. 6. Np plot of DR for transformed data

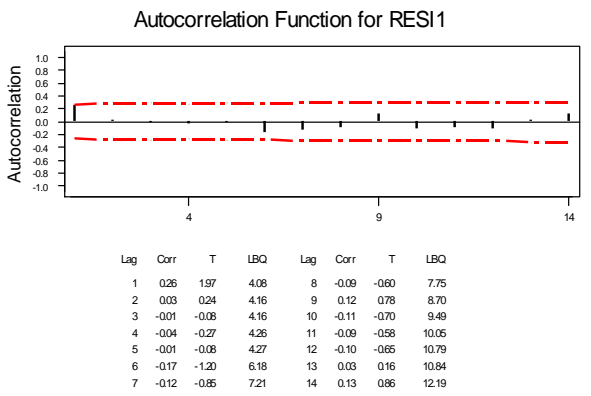

Fig. 8. ACF plot of DR for transformed data 


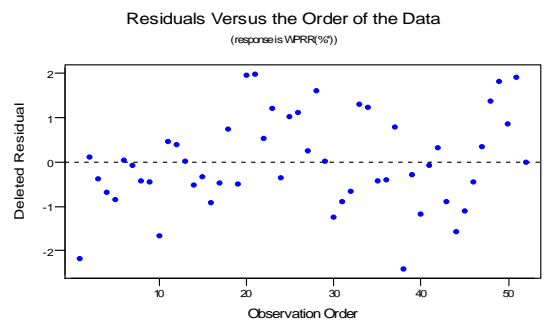

Fig. 9. DR vs fitted value deleting $28^{\text {th }}$ obs.

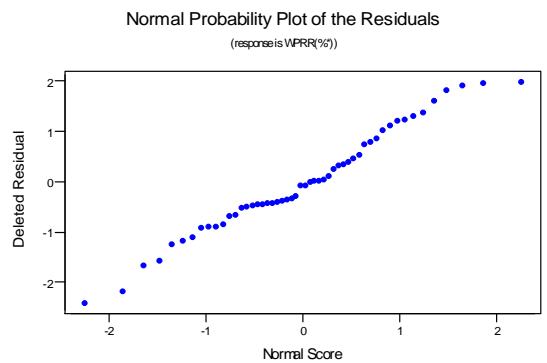

Fig. 11. Hist. of DR deleting $28^{\text {th }}$ obs.

\section{Conclusions}

In order to quantify the impact of climatic change on wheat production in Dinajpur district of Bangladesh, three multiple regression models are made taking several climatic variables during wheat growing period (Nov-Mar) including a dummy variable. According to the results of the model, highly significant effect is found for the dummy variable $\mathrm{dm}$ where one percent increase in $\mathrm{dm}$ increases the yield rate by about $50 \%$. So it may be mentioned that the improved technology such as high yielding variety, irrigation system and other physical inputs may contribute positively to the wheat production and yield rate. Furthermore, approximately significant effect is obtained for the climatic variables of average minimum temperature (tmn), average dry bulb temperature (td) and total rainfall (ttr) and it may be concluded that one percent increase in tmn increases the yield rate by about $2.62 \%$, one percent increase in td decreases the yield rate by about $2.58 \%$ and one percent increase in ttr increases the yield rate by about $0.03 \%$.

\section{References}

BBS (1992). Statistical Year Book of Bangladesh, Statistical Division, Ministry of Science \& Planning, Government of the Peopleôs Republic of Bangladesh.

Chatterjee, S. and Hadi, A. S. (1988). Sensitivity Analysis in Linear Regression. New York: John Wiley \& Sons .

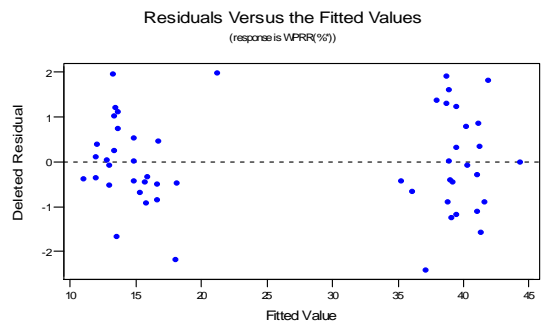

Fig. 10. $\mathrm{Np}$ plot of DR deleting $28^{\text {th }}$ obs.

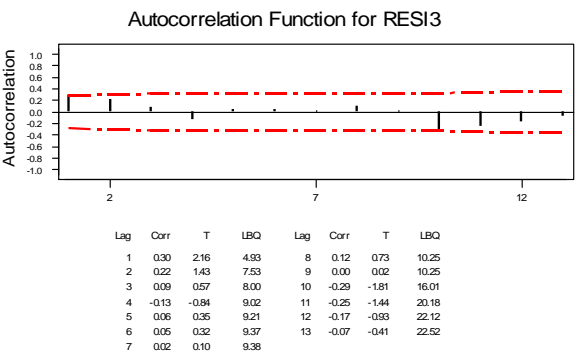

Fig. 12. ACF plot of DR deleting $28^{\text {th }}$ obs.

Chatterjee, S. and Hadi, A. S. (2006). Regression Analysis by Example. (4 ${ }^{\text {th }}$ Edition). New York: John Wiley \& Sons.

Draper N.R. and Smith H. (1981). Applied Regression Analysis. John Wiley \& Sons Inc., NewYork, USA.

Gujarati, D.N. (1995). Basic Econometrics, $3^{\text {rd }}$ ed, McGraw-Hill, New York.

Hamid, M.A. (1991). A Data Base on Agriculture and Food Grains in Bangladesh (1947-48 to 198990), Dhaka, Bangladesh.

Hampel, F.R., Ronchetti, E.M., Rousseeuw, P.J., and Stahel, W. (1986). Robust Statistics: The Approach Based on Influence Function. Wiley, New York.

Hamilton JD (1994). Time Series Analysis. Princeton University Press, Princeton NJ.

Pankraiz A. (1991) ñ Forecasting with Dynamic Regression Modelsò John Wiley \& Sons Inc, NewYork.

Rosenzweig C. and Parry M. (1994). Potential Impact of Climate Change on World Food Supply . Nature 367:133-138. 